IRA International Journal of Management \& Social Sciences ISSN 2455-2267

Vol. 14, Issue 02 (Special Issue) pg. 188-194.

International Conference on Wellbeing: Lifespan Perspectives छo Practices for Sustainable

Communities, 2019.

\title{
Gay Wellbeing in the Life after 377: My Quest for Forming a Sustainable Community
}

\section{Dr Mukul Kr Sarma}

Associate Professor, English Dept., Bapujee College, Sarukshetri, Assam, India.

DOI: $10.21013 /$ jmss.v14.n2sp.p20

(c) Authors.

Type of Review: Peer Reviewed under the Responsibility of the conference's Scientific Committee.

Disclaimer: The copyright to this work is retained by the authorship. This work contains the opinions ${ }^{2}$ views of the authorship solely and the same are not the views or opinions of the IRA. IRA disclaims of any harm or loss caused due to the published content to any party. 


\begin{abstract}
My letter in the Assam Tribune ('Life after 377', September 22, 2018) raises some issues of a sexual minority called the gay community. One of the completely unaddressed problems of gays of Assam is their 'deteriorating mental health as they hide among heterosexuals having the similar gender expressions of heterosexuals, bearing utter suppression, self-loathing, denial and fear'. This 'most discriminated, stigmatized and fearful' community has seen a glimpse of dignity and hope after the Supreme Court's verdict on September 6, 2018, that decriminalized consensual gay-sex. However, it seems, no policy is framed so far for the wellbeing of this community. The paper explores challenges of hidden gay youths-that I have realized communicating and counselling some of them-to conform to their true sexuality as they have been growing in a strict heteronormative milieu suppressing and often ignoring their true sexual desire owing to severe peer, family and societal pressure and lack of sensitization in a gay friendly atmosphere where they could access to some solid references of Assamese gays living truthful, happy life with their gay life-partners. This gay group have members in their mid-twenties, near thirty and in the thirties. They have dated girls, and have been forming heterosexual dreams of starting a family marrying a girl since adolescence; hence, have realised their gay desire quite late. The paper tries to capture their conflicts in the realisation of their true-self; that they still try to deny; and hence, move towards entering a bisexual life with sighs of loss, helplessness and confusions. All of them have been in depression or other psychiatric illnesses-mild to noticeable-which some of them have admitted to having gone through. A majority of them have lost the urge of competing for earning; and hence, financially dependent on the family, although almost all of them have a graduate degree and above. However, there is hardly any psychiatric intervention for promoting their mental health due to their own ignorance and stigma, raising some questions: Will they be able to make a new family happy after marriage?, Should we support the heterosexual marriage of gays?, What is the way out, if not?
\end{abstract}

\title{
1 Introduction
}

Living as a gay shunning the greed of the security and respectability in a heteronormative society is too challenging, yet, thrillingly adventurous with the realization that I am not like those homosexuals "who die before their birth as gay" (Sarma 2013). It is more so as I felt the responsibility to try towards creating a sustainable gay community in a small town called Nalbari, Assam.

\section{How I started}

The feeling of creating the community came to me while my write-ups on gay issues started coming in the Assam Tribune one after another since 2013. A year before 2013, I became free from my PhD research at EFL University-Hyderabad with the award of the degree. That University showed me the path of being what I am in an open-minded milieu for sexual minorities with the presence of a few budding gay rights activists on the campus. The seed of creation of a gay community started during those days, especially after meeting my partner in Assam, who is also a gay rights activist, after coming back from CIEFL completing my MPhil with a hope of getting another study leave for my $\mathrm{PhD}$.

\subsection{Gay rights through The Assam Tribune-mine and others contribution}

Let us observe some letters and poems from The Assam Tribune, that include mine favouring gay rights for establishing their identity 'in a society that is largely hypocritic and homophobic' (Bhagat, 2015), 'creating a gay movement through the print media' (Sarma, 2017d).

\subsection{Gay rights through Letters to the Editor}

Sarma's already mentioned (2018b) letter talks about all pervasive mental health problem of hidden gays even after they marry girls choosing to function as bisexuals "which is not healthy for the society at large".

As a voice against discrimination and stigma towards the LBGT community, Sarma's letter (2017b) points out the necessity of deleting Sec377IPC:

"...the society must be more inclusive which includes sexual minorities like the LGBT community without bias.

However, the society will be so when this politically weakest community would enjoy equal constitutional rights, where a colonial law called Section 377 IPC would not criminalize anymore their private lives.”

Sarma's (2017e) letter raises the question on feasibility of HIV prevention under Sec377IPC that was being enforced since more than a century: "Then, how will our government find out effectively a majority of these people who have been camouflaging as heterosexual; and hence, are not under the purview of the survey that was mostly done on the data gathered from NGOs working on HIV prevention using mostly transgendered subjects?." 
Sarma's other letter (2016a) condemns the brutal killing of a gay-magazine editor and his assistant in Bangladesh:

“...I severely condemn the brutal killing of the editor Julhash Mannan of the Roopban magazine and his associate Tanay Fahim by the al-Qaeda, on April 25. This is a shameful act of gross violation of human rights in modern time. Thus, the LGBT community of the world has lost two pioneers who were courageous enough to raise a voice in their country for this politically very weak minority community..."

Yet another letter of Sarma (2015c) raises the issue of deleting Section 377IPC once again as follows:

"Section 377 IPC that was enforced by British in India way back in 1864, is such a colonial law that has been hampering the freedom in the normal life style of a minority section called the LGBT community. Its presence is very ironical at present, since, way back in 1963 Britain like several other developed countries, herself had amended a similar kind of law in her country and thus, accepted legally the life style of this community. In a similar line, repealing this law in our country also will definitely enhance acceptance and dignity to this very vulnerable and politically weak community."

Medhi's letter (2014) also raises a couple of valid questions regarding this unjustifiable law Section 377 IPC back in force since 11.12.13:

"Now between the Judiciary and Legislature, the LGBT community is caught between the devil and the deep sea. The basic premise itself- that one adult human can dictate life for another- is preposterous. But this is the preposterous reality the community has suffered for centuries now. On the occasion of a year of recriminalization, I humbly ask my fellow human beings that how would they feel if someone considered them incredibly wrong for loving who you love and if someone conceived of laws to actually put them behind the bars."

Further, Sarma's (2013) letter -supporting the Editor on his pro-gay stance and protesting the anti-gay letter of Kailash Sarma published in the same daily-has a strong appeal for repealing this colonial Sec377, giving references from Hinduism in support of homosexuality:

"From your Editorial 'Onus on legislature' (AT, Dec13), it is obvious that the root cause of the contradiction between 'decriminalization' and 'criminalization' of gay sexual practice in India is the Section 377 of Indian Penal Code. Taking its support, the Supreme Court with this verdict has played with the basic rights of those whose need is to practice same-sex behaviour. Because of it, a majority of them dwell the life of closeted homosexuals eventually to die before their births as gays. However, they have been here since time immemorial as solid references can be inferred from Hindu religious texts like Mahabharata with character like Shikhandi or Arjun becoming a transgendered person; in several Hindu religious texts also, we find such examples like in the night of 'Raas', Lord Mahadev becoming a Gopika to be united with Lord Krishna etc.

Thus, Hinduism tolerates and celebrates gay bonding, unlike some other major religions. Hence, obeying a colonially imposed Section of the IPC is not sensible and logical. Ironically, England had legally accepted gay sexuality many years back, like many other developed countries although Christianity considers it a 'gross sin'. We the Indians exploit the contributions of gays from its soil. Hence, Kailash Sharma's opinion in these columns (AT, Dec13) that 'Homosexuality... has never been recognized by the society...' does not hold sense. It is time for LGBT organizations of the country as well as of the world and the concerned authorities including the Legislature to work seriously to delete the colonial Section 377 of the IPC for defending the 'equality' that Indian Constitution vouches for."

Again, Chakraborty's letter (2013) suggests strongly for scrapping Sec377IPC for ensuring the dignity of gays and lesbians:

"Almost every country of the world has accepted homosexuality. Even China has accepted it. A 150-year-old law does not hold water any more... So there should be no second thought scrapping the IPC Section 377."

Protesting a homophobic letter "Gender Divide" by Navanita Barua published in the same daily (March 21, 2013), where she considers homosexuality repulsive, Medhi (2013) responds:

"... I would like to protest its publication on the basis of its inherent bigotry. She supports "free mixing between men and women" and suffers from "the pathos of gender divergence"... she says that "friendship between the same gender is always appreciated and admitted ignoring the abhorrent fact of homosexual fascinations."'”

\subsection{Gay rights through my poems of The Assam Tribune}


Dr Mukul Kr Sarma's several love poems from The Assam Tribune 'try to express his personal gay-love' (Sarma, 2016c). For example, 'A map of heart', published in Horizon, The Assam Tribune (Feb 20, 2015) 'describes the poet and his partner's plans to be united forever to work for the LGBT masses' (Sarma, $2016 \mathrm{c}$ ):

"Have you ever seen that fenced patch of green

On the edge of a bare brown field?

A few farmers have enthusiastically grown paddy-seedlings

For a much-laboured untimely crop, as spring approaches

The lush countryside of our State-

A State still so shockingly remote and alien

Even for the Google maniac 'Indian mainstream'!

The patch, so softly fresh, so lightly vibrant

As if it were a map of a lover's heart,

Who keeps hope year after year amidst all obstacles

While trudging the thorny challenges of a complex terrain-

That good days would eventually come for the realization

Of a long-cherished dream of the expanded minds

To break the thick confined fences of personal benefits

Going beyond the greed of pleasing the senses only

As plans and programmes emerge spontaneously

For taking a sacred vow of being life-long brethren

That work for the welfare of masses, in unison..."

Dr M K Sarma's poem 'Buddha's sunset' published in Horizon, The Assam Tribune (May 16, 2014) 'delineates the beauty of the male body that the poet adores' (Sarma, $2016 \mathrm{c}$ ):

"By pulling off

The orange cloak,

A barren lustrous god

Is simply blazing

In this stimulating warm evening

Of a pleasant season,

To indulge in a luxury bath

With some leisurely dips

In mysteriously golden water

Of the calm mystic river...

After passing a chaotic day

Now, the sun has submerged

In the dark violet waves,

To dream in a deep sleep...

And the god of night

Is eagerly getting ready

Sprinkling perfumes of white flowers

All over a dewy clean body-

Smooth and well defined...

Then the god comes out

On a vast sparkling road

Where the moon above is lost

Under the shine of neon light,

To intoxicate worshippers and devotees..."

Further Sarma's poem 'A new year grief' published in Horizon of The Assam Tribune, (January 23, 2015)' expresses concern to vulnerable minorities including this weak and marginal one-the invincible sexual minority of India, that is revealed clearly in the concluding four lines' (Sarma, 2016a):

"That living freely with dignity is a crime,

While the ignorant lot celebrated overnight

Drenching in drink and dance, the trampling of

The rights of the weak-minorities-Their freedom to live!"

\section{Case study}

Simultaneously writing on gay issues in The Assam Tribune, I started meeting, talking, and counselling, if required, some youths mostly from Nalbari town. I have realised that they are facing a lot of confusions regarding their sexuality as they have been growing in a strictly heteronormative society with heterosexual dreams; and hence, much more exposed to opposite-sex especially through mobile phones. Their speech that I 
have used here bears their confusions and contradictions. I will take here only five cases-all of them are indigenous Assamese youths showing mild to heavy symptoms of deteriorating mental health which "a majority of hidden gays suffer from' (Sarma, 2018b). All of them have experienced dating girls. Only one of them earn adequately to start a family; all others are not in a position of competing properly for getting a good job mainly due to their mental health condition although all of them are a graduate degree or above. Their names are kept anonymous here.

The first one-32 years-is an ultra-busy small company manager-not earning adequately- although being exploited heavily at work. Among the group, he was the most confident and with less obvious homophobia, although I heard his sighs several times while communicating to him face to face. He said to me on an initial day, "I will have to marry a girl, otherwise my elder sister will ask me as to what could be the problem..." However, after one and the half year, when he was about to marry the girl who has been showing interest in him since long, even after knowing and exploring his true gay sexuality confidently, said to me with audible heavy sighs, "although I have talked to the girl and showed her to my family for marriage, I do not love the girl...I love this (homosexual desire of mine!). I have to marry, as I find it difficult to manage the home, even I have no time to think anything, and my mother (widowed, nearing 60) is putting pressure to me for marriage, expressing frequently her displeasure of doing the house hold works alone."

Second one-28 years-has more qualifications and unlike others, he has a high salaried permanent government job. Although he is assertive of his homosexual needs, his intense denial has been recurring cyclically still. He said to me initially, "You have brain washed me to change my intention of marrying a girl. I do not want to read gay issues, because I know what I want (sexually)." Then suddenly one day he telephoned me asking, "Can you give me a male person above 35 years of age with whom I can do everything as I want to explore it (homosexuality)?" Still, he says, "I do not want to read gay issues written by you..."

Third one-33 years- although works in his sister in-law's shop, neither do earn enough for starting a family nor is he in a position to compete for getting better employment. When I encountered him four years back, he said to me although exposing his obvious homosexual desire, "I am not like this (gay). I will go for marriage". After four years he said, "Can you give me a person like you...I will not marry (a girl) soon...Yes, it pains me still when I am alone realising the truth (my homosexuality)."

Fourth one-30 years-is with obvious signs of depression has accepted having it recently, yet untreated still. He left his only hobby, bodybuilding when I first started talking to him two years before that he is resuming these days. He had a girlfriend from an upper caste family while he was in college; the affair did not last. Although he is assertive of forming a gay love relationship, still not ready to explore his homosexual desire. His sighs are quite audible when we talk face to face in private, who even wanted to know its reason that I explained to him also. He said, "Will you be with me if I start working in Guwahati as people there would have no time to suspect anything ... I will not think of marriage for four years, ...I would like to meet you...but my friends will suspect it as some of them may suspect you as gay...I really like to get rid of this problem (not having the urge of working to earn still) by improving myself with your help (practising computer and spoken English), but I fear of being noticed by my friends."

Fifth one-25 years-from Guwahati has been a member of a gay site; and have become a member of GLOW-a virtual gay club of Assam-following my suggestion. When I met him first, he showed obvious symptoms of depression and anxiety disorder with worries of dying soon. He is a meritorious PG student and had experiences of having gay-sex, even unsafe ones. He said to me over a cup of tea with apparent grief on his face, "I have to marry because of my mother...I even have felt love for one of my PG class mates...but anything may happen to me soon (may be out of the fear of indulging in unsafe gay sex, although not being tested for HIV etc. till we met, that I suggested him to do!)”. After our meeting, he said at night that he felt relaxed talking to me. Then, after reading my Facebook posts with my published write-ups on gay issues; and then, going to a GLOW meeting as well as a film watching as per my suggestion, he said, "I feel OK these days... Yes, you were right, I was quite depressed when we met first."

\subsection{Why I have chosen these people}

While I have started raising my voice against Sec 377 IPC, I realised that it is becoming a major hindrance towards preventing HIV (Sarma, 2017d)' as 'gays here have to hide throughout their lives functioning as bisexuals (Sarma, 2018b)'. I felt after meeting these youths who are so vulnerable to be bisexuals sooner or later, that effective introduction of Sex education is necessary to keep the youths healthy (Sarma, 2018 a), and making them value their true sexuality. 


\subsection{My realization of a mental health crisis}

Isensee (1996) states how mental health is a major issue for gay youths. After Sec377IPC is amended on September 6 of 2018 by the SC, I felt that 'with the strength of the verdict the sensitization programme must be implemented where every righteous LGBT person and the Government should take part' (Sarma, 2018 b) to make youths sexually healthy as it has a direct link to a person's physical and mental health. My letter (2018 b) also raises the issue of mental health; and suicide of gays is an issue that remains unaddressed (Sarma, 2017 a) and even unacknowledged so far. Hence, 'sensitization of gay youths is necessary' (Rattnani, 2018; Bhattachrajay, 2018; Sarma, 18b) calling for 'the need of sex education to be introduced from school' (Sarma, 18a; Sarma, 2016d) onward.

\section{Conclusion}

Problems of gays are remaining unaddressed still although homosexuality is legal in India, and so far there is no government scheme covering their well-being that is a far cry at present.

\section{References:}

[1]. Bhagat, Chetan (2015) Making India Awesome. New Delhi: Rupa Publications India Pvt. Ltd.

[2]. Chakraborty, Ashim K. (2013) 'Scrapping IPC Section 377 'Letters to the Editor, in Prafulla Govinda, Barua (ed.), The Assam Tribune, vol x6v, no 343 (Guwahati: Assam Tribune Pvt. Ltd, December 14, 2013).

[3]. Choudhury, Ujjal K. Prof. (2018) 'Incomplete gay rights: what next?', Letters to the Editor, in Prafulla Govinda Barua (ed.), The Assam Tribune, vol x8, no 244 (Guwahati: Assam Tribune Pvt. Ltd, September 9, 2018).

[4]. Farooque, Mehnaz (2014) 'Love in the times of censure', in PrafullaGovindaBarua (ed.), Horizon, The Assam Tribune, vol x7v, no 303 (Guwahati: Assam Tribune Pvt. Ltd, November 7, 2014).

[5]. Isensee, Rik (1999) Reclaiming Your Life, The Gay Men's Guide to Love, Self-Acceptance and Trust. Mumbai: Magna Publishing Co.

[6]. Medhi, Niyor (2013) 'Gender Divide'Letters to the Editor, in PrafullaGovindaBarua (ed.), The Assam Tribune, vol x6v, no 144 (Guwahati: Assam Tribune Pvt. Ltd, March 29, 2013) 6.

[7]. Medhi, Niyor (2014) 'Sec 377IPC', Letters to the Editor, in PrafullaGovindaBarua (ed.), The Assam Tribune, vol x7vi, no 87 (Guwahati: Assam Tribune Pvt. Ltd, December 12, 2014).

[8]. Rattanani, Jagadish (2018) 'LGBT Judgement advances rights for all Indians', Letters to the Editor, in Prafulla Govinda Barua (ed.), The Assam Tribune, vol x8, no 247 (Guwahati: Assam Tribune Pvt. Ltd, September 12, 2018).

[9]. Sarma, Dr Mukul K. (2013) 'Section 377IPC: Illogical, Insensible', Letters to the Editor, in Prafulla Govinda Barua (ed.), The Assam Tribune, vol x7v, no 345 (Guwahati: Assam Tribune Pvt. Ltd, December 16, 2013).

[10]. Sarma Dr Mukul K.(2015a) 'Repealed Laws', Letters to the Editor, in Prafulla Govinda Baruah (ed.), The Assam Tribune, vol x7vii, no 144 (Guwahati: Assam Tribune Pvt. Ltd, May 30, 2015).

[11]. Sarma Dr Mukul K. (2015b) "Hidden LGBT world in 'Weight Loss", paper presented in a National Seminar on "Reflection of the Changing Indian Society in Indian English Fiction" (Organized by English Dept. of MNC Girls' College, Nalbari, September 11-12, 2015).

[12]. Sarma, Dr Mukul K.(2015c)'Empathy for the Invisible, Vulnerable Section of our Students'. In: DrCharnalata Das and Dr Sultan Ali Ahmed (eds.) (Sarobhog: Barnagar.Sauvenir-62 ${ }^{\text {nd }}$ Annual Conference of ACTA: Impression Offset Press, 2015), 195-200.

[13]. Sarma, Dr Mukul K. (2016a)"Negotiating acceptance, identity and space for the LGBT community" paper presented in a National Seminar on "Negotiating Language, Literature and Culture: A North East Perspective" (Organized by English Dept., Assam University, Diphu Campus, March 10-11, 2016)

[14]. Sarma, Dr Mukul K. (2016b) 'B'desh killings', Letters to the Editor, in PrafullaGovindaBarua (ed.), The Assam Tribune, vol x7viii, no 120 (Guwahati: Assam Tribune Pvt. Ltd, May 6, 2016).

[15]. Sarma, Dr Mukul K (2016c) "Shakespeare's poems: Gay love of invisible LGBT community and the Assamese response" paper presented in a National Seminar on "Reading Shakespeare in the $21^{\text {st }}$ Century " (Organized by English Dept., BH College, Howly, August 5-6, 2016).

[16]. Sarma, Dr Mukul K (2016d) "What is the best way to impart sex education among children?", People Speak', in Prafulla Govinda Barua (ed.), The Assam Tribune, Sunday Reading, vol x7viii, no 315 (Guwahati: Assam Tribune Pvt. Ltd, November 20, 2016).

[17]. Sarma, Dr Mukul K (2017a) "The struggle for the LGBT identity, post December 11, 2013 Supreme Court Verdict" paper presented, International Seminar on Language, Ethnicity, Identity: 21th century Perspectives organized by ELT@I, Assam Chapter, held in Tinsukia College, Tinsukia, (11-12 February, 2017).

[18]. Sarma, Dr Mukul K (2017b) 'Hope for $L G B T$ ', Letters to the Editor, in Prafulla Govinda Barua (ed.), The Assam Tribune, vol x7ix, no 90 (Guwahati: Assam Tribune Pvt. Ltd, April 5, 2017).

[19]. Sarma, Dr Mukul K (2017c) 'Is marriage an outdated institution?", People Speak', in Prafulla Govinda Baruah (ed.), The Assam Tribune, Sunday Reading, vol x7ix, no 278 (Guwahati: Assam Tribune Pvt. Ltd, October 8, 2017).

[20]. Sarma, Dr Mukul K (2017d) "The Media towards Gay Rights after December 11, 2013, Supreme Court Verdict" paper presented, International Seminar on Media and Politics: held in Assam University, Silchar, (6-7 December, 2017). 
[21]. Sarma, Dr Mukul K (2017e) 'Woes of LGBT people', Letters to the Editor, in Prafulla Govinda Baruah (ed.), The Assam Tribune, Sunday Reading, vol x7ix, no 340 (Guwahati: Assam Tribune Pvt. Ltd, December 11, 2017).

[22]. Sarma, Dr Mukul K (2018a) 'Sex Education', Letters to the Editor, in Prafulla Govinda Barua (ed.), The Assam Tribune, Sunday Reading, vol x8, no 145 (Guwahati: Assam Tribune Pvt. Ltd, May 31, 2018).

[23]. Sarma, Dr Mukul K (2018b) 'Life after 377', Letters to the Editor, in Prafulla Govinda Barua (ed.), The Assam Tribune, Sunday Reading, vol x8, no 257 (Guwahati: Assam Tribune Pvt. Ltd, September 22, 2018).

[24]. Tharoor, Shashi (2016) "Decriminalize Homosexuality", an online petition to the Prime Minister, (https://www.change.org/p/shri-narendra-modi-decriminalise-homosexuality). 